\title{
Binary Black Holes Algorithm
}

\author{
Mostafa Nemati \\ Computer Science Department, \\ Tabari University of Babol, Iran
}

\author{
Hossein Momeni \\ Agricultural Sciences and \\ Natural Resources University of \\ Gorgan
}

\author{
Navid Bazrkar \\ Computer Science Department, \\ Tabari University of Babol, Iran
}

\begin{abstract}
In this paper we adapt black holes optimization algorithms for binary search spaces by applying a sigmoid transformation to the gravity and electrical forces. Black holes algorithm is a Swarm Algorithm inspired of Black Holes for Optimization Problems. We supposes each solution of problem as a binary black hole and after calculating the gravity and electrical forces use a mapping function for set it. The proposed method is verified using several benchmark problems used in the area of optimization. The experimental results on different benchmarks show that the performance of the proposed algorithm is better than BPSO (Binary Particle Swarms Optimization), BAFS (Binary Artificial Fish Swarm Algorithm) and GA (Genetic Algorithm).
\end{abstract}

\section{General Terms}

Artificial intelligence, Swarm algorithms, Black holes algorithm.

\section{Keywords}

Binary Black Hole, binary search spaces, Optimization Problem, Sigmoid Function, gravity and electrical forces.

\section{INTRODUCTION}

There are different methods for solving an optimization problem. Some of these methods are inspired from natural processes. These methods usually start with an initial set of variables and then evolve to obtain the global minimum or maximum of the objective function [1]. Swarm intelligent algorithms have attracted significant attention in recent years. Algorithm behavior models the natural behavior of different phenomena [2]. Intensification and diversification are two main features of the meta-heuristic algorithms. The intensification phase searches around the current best solutions and selects the best candidates or solutions. The diversification phase ensures that the algorithm explores the search space more efficiently [3].

There are so many problems which have discrete natures. Moreover in many applications, solving problems which have concrete space are done in discrete space. Hence, since both concrete and discrete problems are solvable in a discrete space, need to have discrete search algorithms are felt.The majority of Optimization Problems are defined in the discrete space. Hence, proposing an efficient algorithm to solve the problems has become an attractive subject in recent years [4]. BPSO is a global optimization algorithm for discrete problems proposed by Kennedy and Eberhart [5] in 1997. In the PSO algorithm, each particle searches for an optimal solution to the objective function in the search space [6]. SA is another metaheuristic optimization which can be employed in the discrete search space. Kirkpatrick et al, proposed the algorithm based on the way thermodynamic systems go from one energy level to another in 1983 [7].

The rest of this paper is organized as follows: The next section gives a review about black holes algorithm. The proposed algorithms (binary black holes) introduced in section 3. In section 4 the computational and experimental results are presented to evaluate the performance of the proposed method. Finally, in Section 5 includes conclusions and discussions.

\section{BLACK HOLES ALGORITHM}

A black hole is a region of space-time whose gravitational field is so strong that nothing which enters it, not even light, can escape. The theory of general relativity predicts that a sufficiently compact mass will deform space-time to form a black hole. Around a black hole there is a mathematically defined surface called an event horizon that marks the point of no return. If anything moves close to the event horizon or crosses the Schwarzschild radius it will be absorbed into the black hole and permanently disappear. The existence of black holes can be discerned by its effect over the objects surrounding it [8]. It is called "black" because it absorbs all the light that hits the horizon, reflecting nothing, just like a perfect black body in thermodynamics $[9,10]$. A black hole has only three independent physical properties: mass, charge, and angular momentum [11]. A charged black hole repels other like charges just like any other charged object. The simplest black holes have mass but neither electric charge nor angular momentum.

The black hole algorithm proposed in the paper [12] by Nemati et al. In this algorithm at first generated a random population a then evolve it in the generations to earn best solution. In this algorithm initialized step is production of a number of random black holes as initial solution. Each of this black holes has own position, mass and electrical charge. The name of this step is called big bang. Each of black holes is a solution for the problem.

$$
\text { black hole }_{i}=\left\{\begin{array}{c}
\text { Position }=X \\
\text { mass }=m \\
\text { charged }=q
\end{array} \quad i=1,2, \ldots, N\right.
$$

At second step, fitness evaluated for each of these black holes as formula (2), which $\mathrm{f}$ is Cost function and determine the best black hole in the population and call it global best.

$$
\text { fitness }_{i-t h}=f\left(\text { black hole }_{i}\right) \quad i=1,2, \ldots, N
$$

In third step, evaluated the new position of the each black hole by calculating the forces .In algorithm each black hole attracted to the global best by gravity force and attracted to the local best position by the Coulomb's law, In the other words we assume FG (gravity force) for the global search and FQ (electricity force) for the local search. FG and FQ are calculated by (3) and (4) formulas.

$$
\begin{aligned}
& F g_{i}=G \frac{m_{\text {gbest }} * m_{i}}{r^{2}} \quad i=1,2, \ldots, N \\
& F q_{i}=k \frac{q_{\text {lbest }} * q_{i}}{r^{2}} \quad i=1,2, \ldots, N
\end{aligned}
$$


Where Fg is gravitational force, $\mathrm{Fq}$ is electrical force, $\mathrm{m}_{\text {gbest }}$ is mass of global best black hole, and $\mathrm{q}_{\mathrm{lbest}}$ is charge of local best black hole. $\mathrm{G}$ and $\mathrm{K}$ are constant number. When $\mathrm{Fg}$ and $\mathrm{Fq}$ were calculated, then we earn new position of the black holes by formula (5).

$$
\begin{aligned}
& X_{i}(t+1)=X_{i}(t)+\operatorname{random} 1 * F g+ \\
& \text { random } 2 * F q \quad i=1,2, \ldots N
\end{aligned}
$$

Where $X_{i}(t+1)$ and $X_{i}(t)$ are the position of $i$-th black hole at iteration $\mathrm{t}+1$ and $\mathrm{t}$, respectively .and $\mathrm{Fg}$ is gravitational force, $\mathrm{Fq}$ is electrical force. And also random1, random 2 are random number between $[0,1]$.

The algorithm also used of Hawking radiation as. At this step is the same mutation step in genetic algorithm.by hawking radiation the algorithm escape from trapping in local optimums. In this step, by randomly we changed the position of black holes. With this work the algorithm escape from trapping in local extermums.

\section{BINARY BLACK HOLES ALGORITHM (PROPOSED METHOD)}

In many optimization problems the searching should be performed in the binary space. Hence it is desirable for these optimization algorithms presenting Binary version. In the binary space, the explorer particles move in the zero and one space. Consider a hypercube which labeled each of the corners with binaries. Each of these corners is one solution. In our method, the masses move between these corners to search the solution space. The movement of the particle in any dimension changes Ones to Zeros and vice versa.

As the basic black holes algorithm [12] operates in continuous and real number space, it cannot be used to optimize the pure binary problems. To tackle this problem, we proposed binary black holes algorithm. For binary search space, we have adapted the black holes to search in binary spaces, by applying a sigmoid transformation to the gravity and electrical forces to squash this forces s into a range $[0,1]$, and force the new values of the locations of black holes to be 0 's or 1's.

In this paper, the Gravity and Electrical forces of each Black Hole are considered as a Probability function in any dimension and the Black Holes move based on these probabilities. In fact, in the binary version of our method, $\mathrm{Fg}+\mathrm{Fq}$ represents the probability of being the $\mathrm{X}_{\mathrm{i}}^{\mathrm{d}}$ One or Zero instead of displacement of the particles. The sigmoid function transforms the input, which can have any value between plus and minus infinity, into a reasonable value in the range between 0 and 1. Graph of sigmoid function showed in the figure 1.

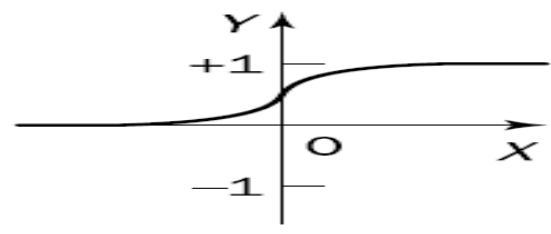

Figure1. Gragh of sigmoid function

$$
\operatorname{Sigmoid}\left(\mathrm{F}_{\mathrm{g}}+\mathrm{F}_{\mathrm{q}}\right)=\frac{1}{1+\mathrm{e}^{-\left(\mathrm{Fg}+\mathrm{F}_{\mathrm{q}}\right)}}
$$

The equation for updating positions Eqn. (5) is then replaced by Eql (7).

if rand $<\frac{1}{1+\mathrm{e}^{-\left(\mathrm{Fg}^{+} \mathrm{Fq}\right)}}$ then $\mathrm{X}_{\mathrm{i}}^{\mathrm{d}}(\mathrm{t}+1)=$
complement $\left(\mathrm{X}_{\mathrm{i}}^{\mathrm{d}}(\mathrm{t})\right)$ else $\mathrm{X}_{\mathrm{i}}^{\mathrm{d}}(\mathrm{t}+1)=\mathrm{X}_{\mathrm{i}}^{\mathrm{d}}(\mathrm{t})$

Where rand is a random number between $[0,1]$.

Based on the above the main steps in the proposed binary black hole algorithm are summarized as follow Pseudo-code:

Input: objective function

Output: optimal solution

Initialize a binary population of black holes with random locations in the search space (Binary Big Bang)

While (termination criteria satisfy) do

For each black hole, evaluate the objective function

Select the global best black hole that has the best fitness value

Calculate the Sigmoid function by Eq. (6)

Change the location of each black hole according to Eq. (7)

Do Hawking radiation (as mutation in algorithm)

End of while

\section{THE EXPERIMENTAL RESULTS}

In this section the proposed binary black hole algorithm (BBLA) is tested with benchmark functions. Six benchmark functions with a variety of complexity are used to evaluate the performance of proposed method. Benchmark function and properties is show on table 1 . The performance of the proposed algorithm is compared against well-known algorithm like than BPSO (Binary Particle Swarms Optimization), BAFS (Binary Artificial Fish Swarm Algorithm) and GA (Genetic Algorithm). The experiments for each function run for 10 times and average of result is reported. In figures 5 for better distinction of four algorithms the Y-axis (fitness) is on logarithmic scale.Figures 3-14 show the Convergence performance of GA, BPSO, PFSA and BBLA (propose algorithm) on 6 Benchmark function (100D and 1000D) - $\mathrm{X}$-axis is generation and $\mathrm{Y}$-axis is fitness on logarithmic scale. 


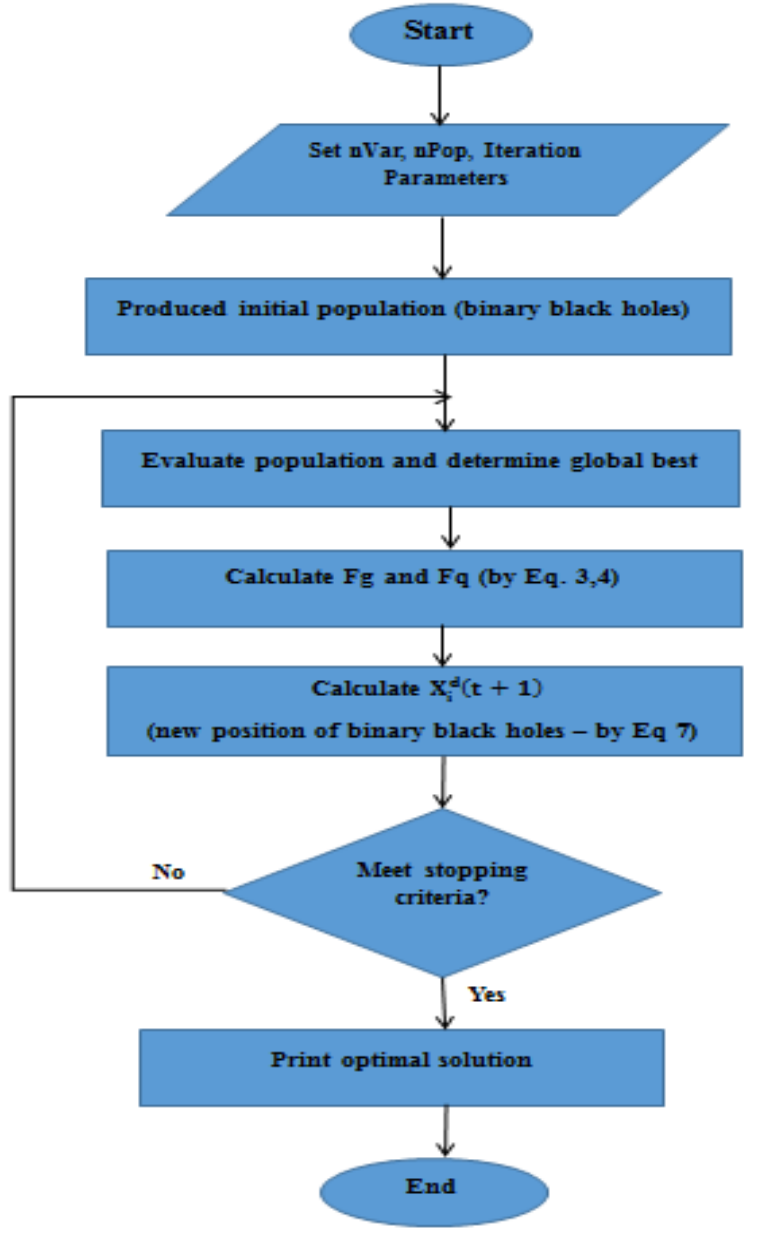

Figure2. Flow chart of binary black holes algorithm
Table 1. Benchmark Function

\begin{tabular}{|c|c|c|c|}
\hline $\mathbf{F}$ & Equation & $\begin{array}{c}\text { Dimension } \\
\mathrm{s}\end{array}$ & $\begin{array}{c}\mathbf{M i} \\
\mathbf{n}\end{array}$ \\
\hline$f_{1}$ & $\begin{array}{l}f_{1}(x) \\
=\sum_{i=1}^{n}\left[x_{i}^{2}-10 \cos \left(2 \pi x_{i}\right)\right. \\
+10]\end{array}$ & 100,1000 & 0 \\
\hline$f_{2}$ & $f_{2}(x)=\sum_{i=1}^{n}\left(\left[x_{i}+0.5\right]\right)^{2}$ & 100,1000 & 0 \\
\hline$f_{3}$ & $\begin{aligned} f_{3}(x)=\sum_{i=1}^{n}[100 & \left(x_{i+1}\right. \\
& \left.-x_{i}^{2}\right)^{2} \\
& \left.+\left(x_{i}-1\right)^{2}\right]\end{aligned}$ & 100,1000 & 0 \\
\hline$f_{4}$ & $f_{1}(x)=\sum_{i=1}^{n}\left|x_{i}\right|+\prod_{i=1}^{n}\left|x_{i}\right|$ & 100,1000 & 0 \\
\hline$f_{5}$ & $\begin{array}{l}f_{5}(x) \\
=-20 \exp \left(-0.2 \sqrt{\frac{1}{n} \sum_{i=1}^{n} x_{i}^{2}}\right. \\
-\exp \left(\frac{1}{n} \sum_{i=1}^{n} \cos \left(2 \pi x_{i}\right)\right) \\
+20+e\end{array}$ & 100,1000 & 0 \\
\hline$f_{6}$ & $\begin{array}{l}f_{6}(x) \\
=\frac{1}{4000} \sum_{i=1}^{n} x_{i}^{2} \\
-\prod_{i=1}^{n} \cos \left(\frac{x_{i}}{\sqrt{i}}\right)+1\end{array}$ & 100,1000 & 0 \\
\hline
\end{tabular}




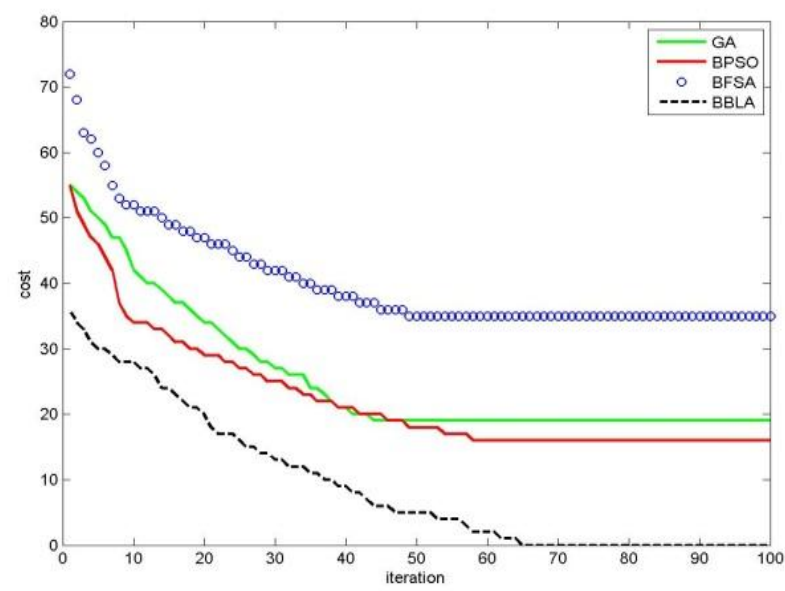

Figure3 . F1 function 100D

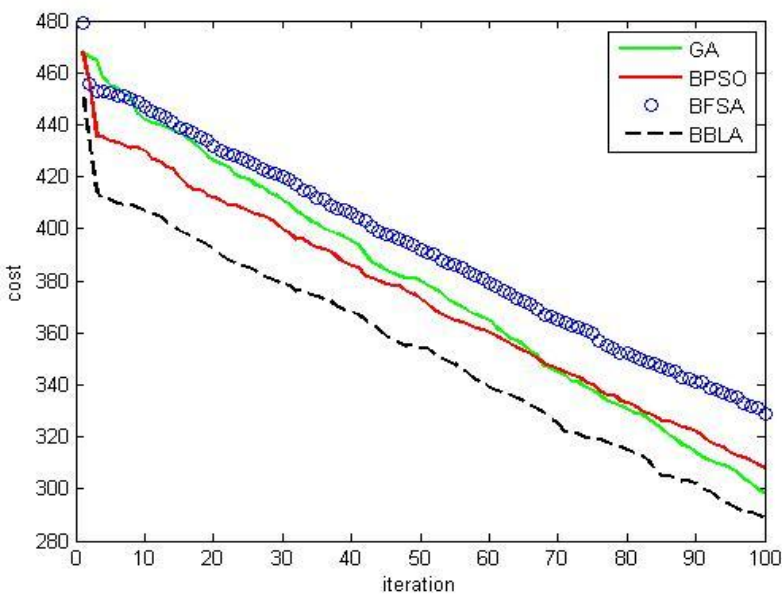

Figure4 . F1 function 1000D

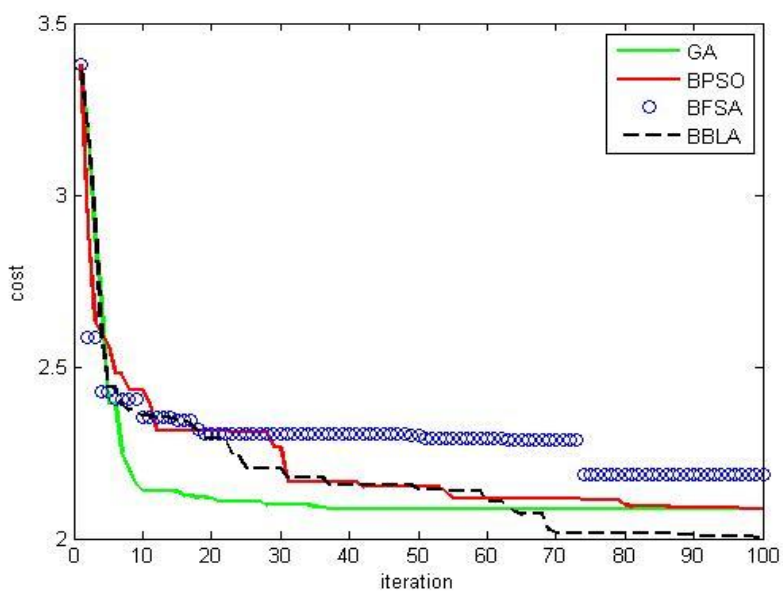

Figure5. F2 function 100D

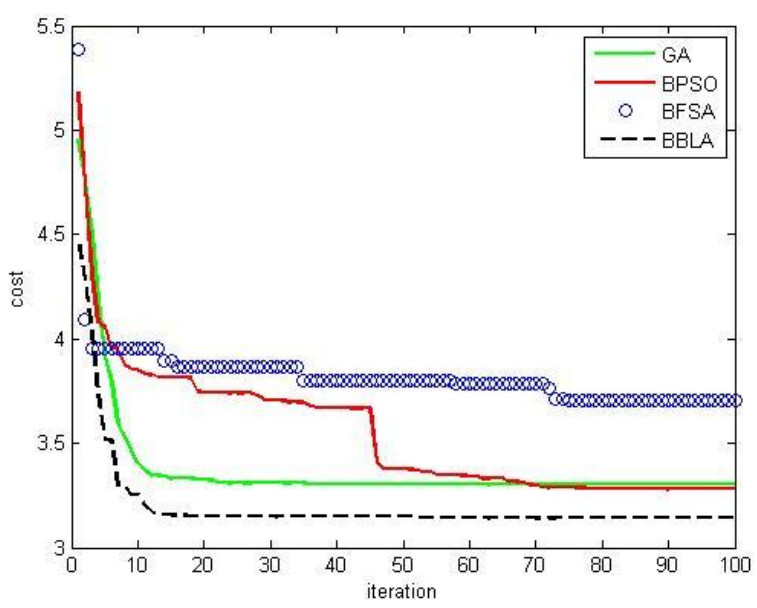

Figure6 . F2 function 1000D

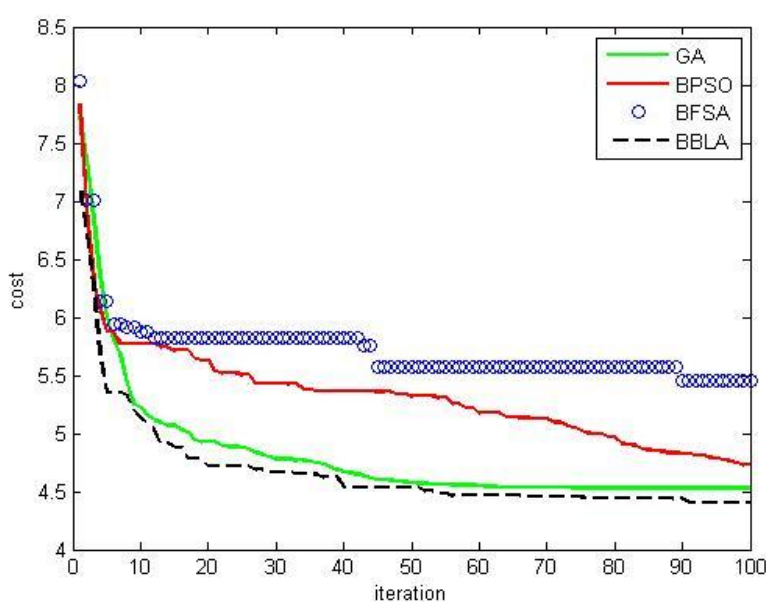

Figure7 . F3 function 100D

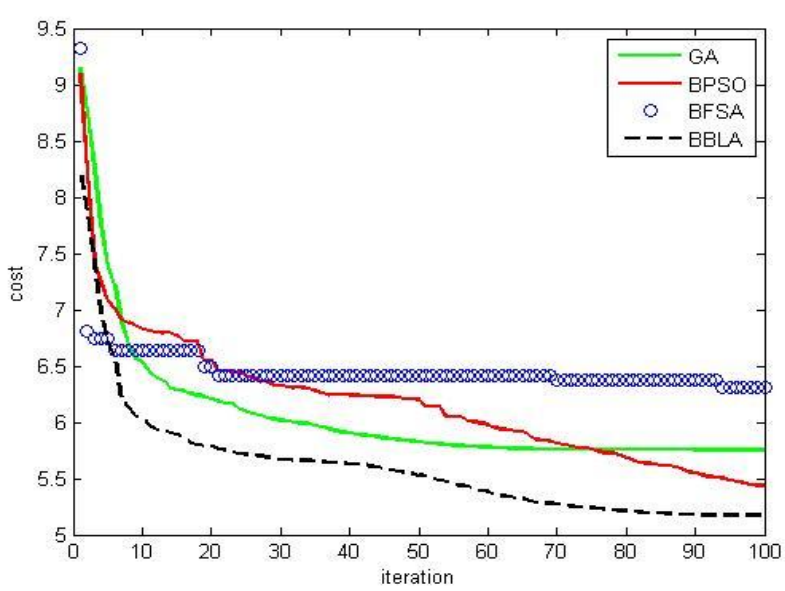

Figure8 . F3 function 1000D 


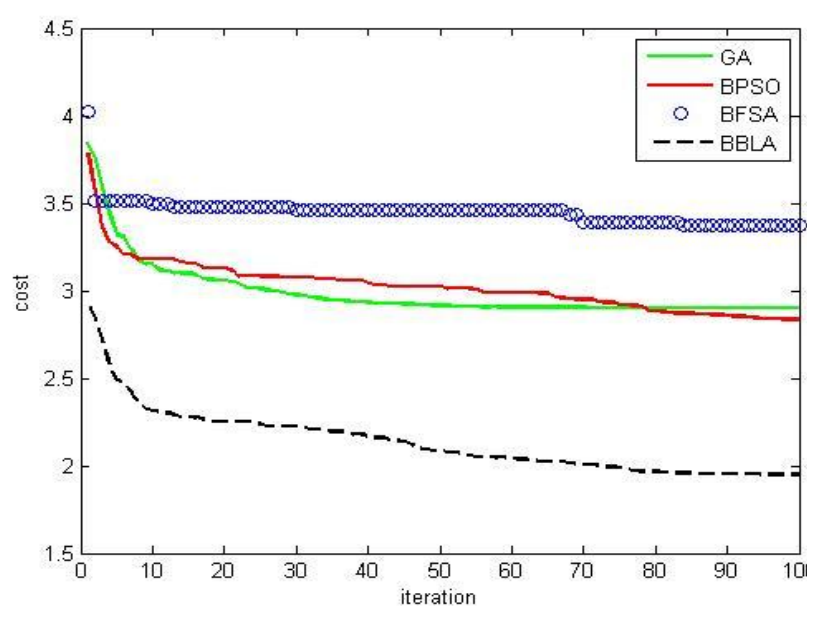

Figure9 . F4 function 100D

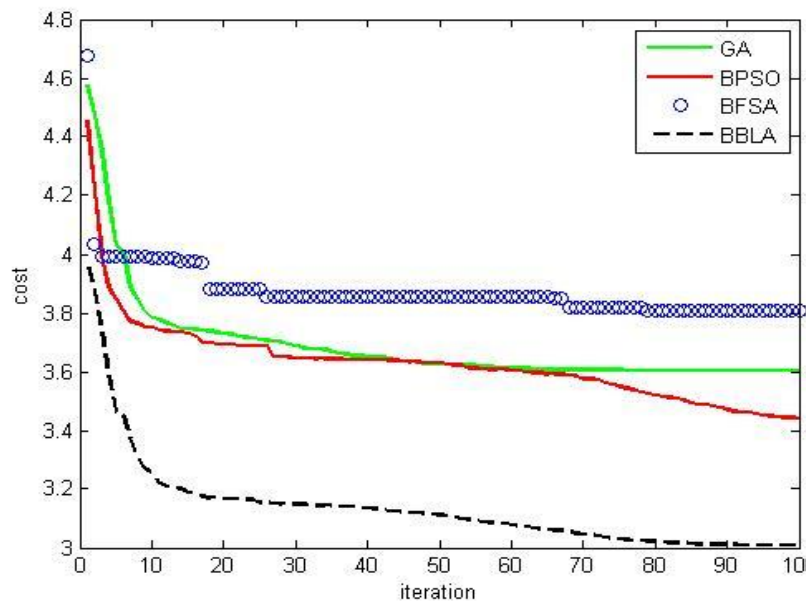

Figure10 . F4 function 1000D

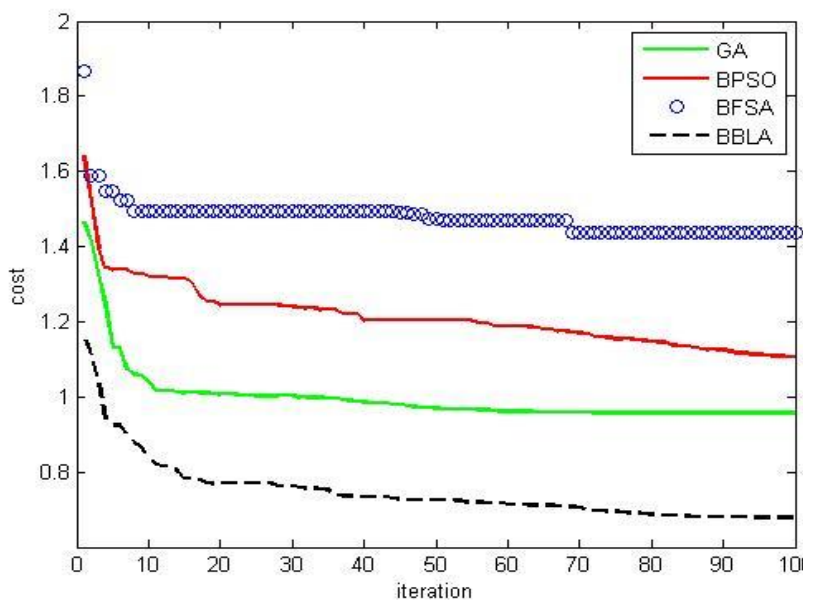

Figure11 . F5 function 100D

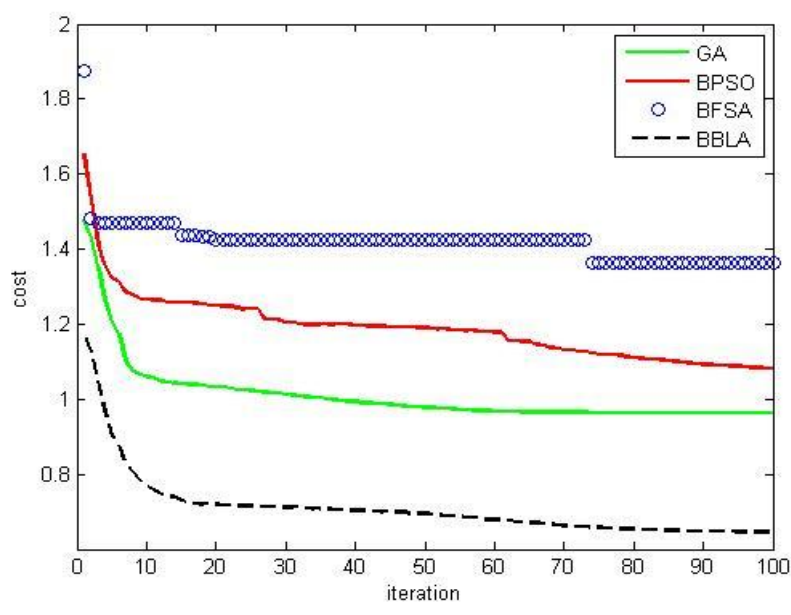

Figure12 . F5 function 1000D

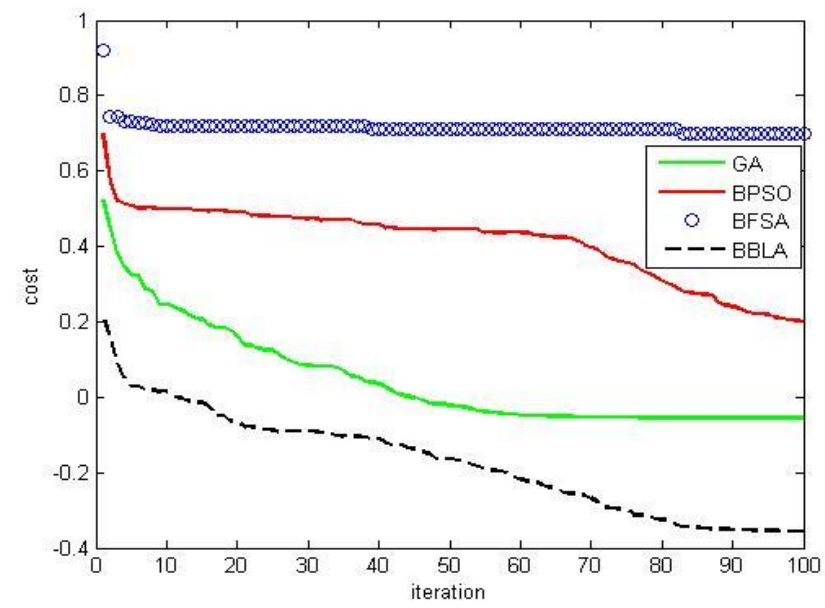

Figure13 . F6 function 100D

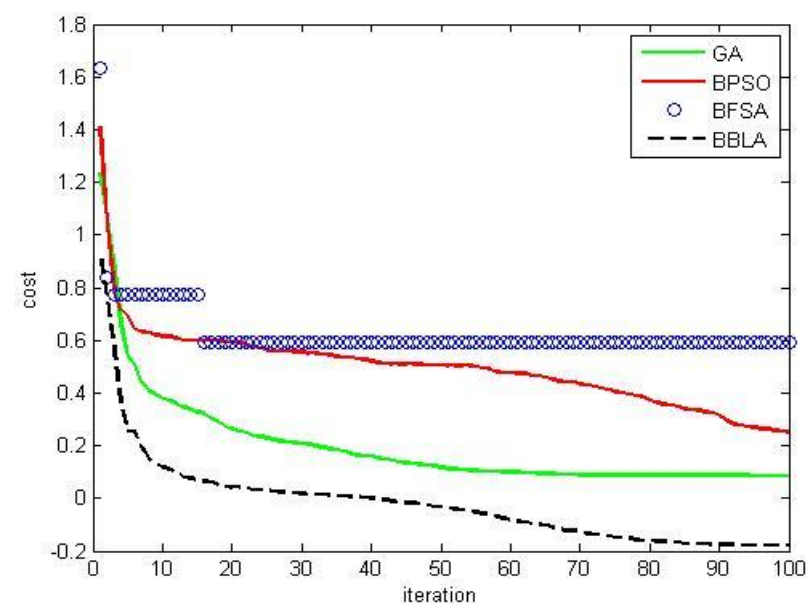

Figure14 . F6 function 1000D 
Table 2. Global optimization results for function $1\left(f_{1}\right)$

\begin{tabular}{|c|c|c|c|c|}
\hline $\begin{array}{c}\text { Algorith } \\
\mathbf{m}\end{array}$ & $\begin{array}{c}\text { Populatio } \\
\mathbf{n} \text { size }\end{array}$ & $\begin{array}{c}\text { Dimensio } \\
\mathbf{n}\end{array}$ & $\begin{array}{c}\text { Iteratio } \\
\mathbf{n}\end{array}$ & $\begin{array}{c}\text { Best } \\
\text { Answe } \\
\mathbf{r}\end{array}$ \\
\hline GA & 100 & 100 & 100 & 19 \\
\hline BPSO & 100 & 100 & 100 & 16 \\
\hline BFSA & 100 & 100 & 100 & 35 \\
\hline BBLA & 100 & 100 & 100 & $\mathbf{0}$ \\
\hline GA & 1000 & 1000 & 100 & 298 \\
\hline BPSO & 1000 & 1000 & 100 & 308 \\
\hline BFSA & 1000 & 1000 & 100 & 329 \\
\hline BBLA & 1000 & 1000 & 100 & $\mathbf{2 8 9}$ \\
\hline
\end{tabular}

Table 3. Global optimization results for function $2\left(f_{2}\right)$

\begin{tabular}{|c|c|c|c|c|}
\hline $\begin{array}{c}\text { Algorith } \\
\mathbf{m}\end{array}$ & $\begin{array}{c}\text { Populatio } \\
\mathbf{n} \text { size }\end{array}$ & $\begin{array}{c}\text { Dimensio } \\
\mathbf{n}\end{array}$ & $\begin{array}{c}\text { Iteratio } \\
\mathbf{n}\end{array}$ & $\begin{array}{c}\text { Best } \\
\text { Answe } \\
\mathbf{r}\end{array}$ \\
\hline GA & 100 & 100 & 100 & 122 \\
\hline BPSO & 100 & 100 & 100 & 122 \\
\hline BFSA & 100 & 100 & 100 & 154 \\
\hline BBLA & 100 & 100 & 100 & $\mathbf{1 0 1}$ \\
\hline GA & 1000 & 1000 & 100 & 667 \\
\hline BPSO & 1000 & 1000 & 100 & 382 \\
\hline BFSA & 1000 & 1000 & 100 & 630 \\
\hline BBLA & 1000 & 1000 & 100 & $\mathbf{3 1}$ \\
\hline
\end{tabular}

Table 4. Global optimization results for function $3\left(f_{3}\right)$

\begin{tabular}{|c|c|c|c|c|}
\hline $\begin{array}{c}\text { Algorith } \\
\mathbf{m}\end{array}$ & $\begin{array}{c}\text { Populatio } \\
\mathbf{n} \text { size }\end{array}$ & $\begin{array}{c}\text { Dimensio } \\
\mathbf{n}\end{array}$ & $\begin{array}{c}\text { Iteratio } \\
\mathbf{n}\end{array}$ & $\begin{array}{c}\text { Best } \\
\text { Answer }\end{array}$ \\
\hline GA & 100 & 100 & 100 & 4.6788 \\
\hline BPSO & 100 & 100 & 100 & 4.7671 \\
\hline BFSA & 100 & 100 & 100 & 5.4523 \\
\hline BBLA & 100 & 100 & 100 & $\mathbf{4 . 4 6 7 8}$ \\
\hline GA & 1000 & 1000 & 100 & $\begin{array}{c}7.1348 \mathrm{e}+0 \\
04\end{array}$ \\
\hline BPSO & 1000 & 1000 & 100 & $\begin{array}{c}3.9011 \mathrm{e}+0 \\
04\end{array}$ \\
\hline BFSA & 1000 & 1000 & 100 & $\begin{array}{c}1.6801 \mathrm{e}+0 \\
05\end{array}$ \\
\hline BBLA & 1000 & 1000 & 100 & $\begin{array}{c}\mathbf{1 . 0 0 6 4 e + 0} \\
\mathbf{0 5}\end{array}$ \\
& & & & \\
\hline
\end{tabular}

Table 5. Global optimization results for function $4\left(f_{4}\right)$

\begin{tabular}{|c|c|c|c|c|}
\hline $\begin{array}{l}\text { Algorith } \\
\text { m }\end{array}$ & $\begin{array}{l}\text { Populatio } \\
\text { n size }\end{array}$ & $\begin{array}{c}\text { Dimensio } \\
\mathbf{n}\end{array}$ & $\begin{array}{c}\text { Iteratio } \\
\mathbf{n}\end{array}$ & $\begin{array}{c}\text { Best } \\
\text { Answer }\end{array}$ \\
\hline GA & 100 & 100 & 100 & 99.7924 \\
\hline BPSO & 100 & 100 & 100 & 97.5924 \\
\hline BFSA & 100 & 100 & 100 & 196.0634 \\
\hline BBLA & 100 & 100 & 100 & 88.9392 \\
\hline GA & 1000 & 1000 & 100 & $\begin{array}{c}1.0058 \mathrm{e}+0 \\
03\end{array}$ \\
\hline BPSO & 1000 & 1000 & 100 & 919.7287 \\
\hline BFSA & 1000 & 1000 & 100 & $\begin{array}{c}1.2903 \mathrm{e}+0 \\
03\end{array}$ \\
\hline BBLA & 1000 & 1000 & 100 & $\begin{array}{c}1.0009 \mathrm{e}+0 \\
03\end{array}$ \\
\hline
\end{tabular}


Table 6. Global optimization results for function $5\left(f_{5}\right)$

\begin{tabular}{|c|c|c|c|c|}
\hline $\begin{array}{c}\text { Algorith } \\
\mathbf{m}\end{array}$ & $\begin{array}{c}\text { Populatio } \\
\mathbf{n} \text { size }\end{array}$ & $\begin{array}{c}\text { Dimensio } \\
\mathbf{n}\end{array}$ & $\begin{array}{c}\text { Iteratio } \\
\mathbf{n}\end{array}$ & $\begin{array}{c}\text { Best } \\
\text { Answe } \\
\mathbf{r}\end{array}$ \\
\hline GA & 100 & 100 & 100 & 4.5315 \\
\hline BPSO & 100 & 100 & 100 & 4.2580 \\
\hline BFSA & 100 & 100 & 100 & 5.4486 \\
\hline BBLA & 100 & 100 & 100 & $\mathbf{4 . 1 7 6 0}$ \\
\hline GA & 1000 & 1000 & 100 & 4.5994 \\
\hline BPSO & 1000 & 1000 & 100 & 4.0266 \\
\hline BFSA & 1000 & 1000 & 100 & 4.6151 \\
\hline BBLA & 1000 & 1000 & $\mathbf{1 0 0}$ & $\mathbf{4 . 0 0 8 8}$ \\
\hline
\end{tabular}

Table 7. Global optimization results for function $6\left(f_{6}\right)$

\begin{tabular}{|c|c|c|c|c|}
\hline $\begin{array}{c}\text { Algorith } \\
\mathbf{m}\end{array}$ & $\begin{array}{c}\text { Populatio } \\
\mathbf{n} \text { size }\end{array}$ & $\begin{array}{c}\text { Dimensio } \\
\mathbf{n}\end{array}$ & $\begin{array}{c}\text { Iteratio } \\
\mathbf{n}\end{array}$ & $\begin{array}{c}\text { Best } \\
\text { Answe } \\
\mathbf{r}\end{array}$ \\
\hline GA & 100 & 100 & 100 & 0.4394 \\
\hline BPSO & 100 & 100 & 100 & 0.5303 \\
\hline BFSA & 100 & 100 & 100 & 0.9963 \\
\hline BBLA & 100 & 100 & 100 & $\mathbf{0 . 1 4 0 6}$ \\
\hline GA & 1000 & 1000 & 100 & 0.6102 \\
\hline BPSO & 1000 & 1000 & 100 & 0.5970 \\
\hline BFSA & 1000 & 1000 & 100 & 0.7799 \\
\hline BBLA & 1000 & 1000 & 100 & $\mathbf{0 . 3 6 2 8}$ \\
\hline
\end{tabular}

\section{CONCLUSION}

In this paper we adapt black holes optimization algorithms for binary discrete search spaces by applying a sigmoid transformation to the gravity and electrical forces. Each solution of problem is a binary black hole and after calculating the gravity and electrical forces use a mapping function for set it in binary space. The experimental results on different benchmarks show that the performance of the proposed algorithm is better than other similar algorithms. To continue our work we decide to adapt black holes algorithms in multi objective optimization problems and introduced multi objective black hole algorithm (MBLA).

\section{REFERENCES}

[1] Ramin Rajabioun, "Cuckoo Optimization Algorithm", Applied Soft Computing 11 5508-5518, Published by Elsevier (2011).

[2] Hsing-Chih Tsai, Yong-Huang Lin, "Modification of the fish swarm algorithm with particle swarm optimization formulation and communication behavior", Applied Soft Computing 11 ,5367-5374, Published by Elsevier (2011).

[3] Amir Hossein Gandomi , Amir Hossein Alavi, "Krill herd: A new bio-inspired optimization algorithm", Commun Nonlinear Sci Numer Simulat 17, 4831-4845, Published by Elsevier (2012).

[4] Zahra Beheshti, Siti Mariyam Shamsuddin, Siti Sophiayati Yuhaniz, "Binary Accelerated Particle Swarm Algorithm (BAPSA) for discrete optimization problems", Journal of Global Optimization, December, Published by Springer (2012).

[5] Kennedy, J., Eberhart, R.C.: A discrete binary version of the particle swarm algorithm. In: Proceedings of IEEE International Conference on Computational Cybernetics and Simulation, pp. 4104-4109. Orlando, USA (1997).

[6] H. Omranpour, et al., " Dynamic Particle Swarm Optimization for Multimodal Function," International Journal of Artificial Intelligence (IJ-AI), Vol. 1, No. 1, ISSN: 2252-8938, (2012).

[7] Kirkpatrick, S., Gelatto, C.D., Vecchi, M.P.: "Optimization by simulated annealing". Science 220, 671-680 (1983).

[8] L. Kaper, E. Heuvel, P. Woudt, R. Giacconi, Black hole research past and future, in: Black Holes in Binaries and Galactic Nuclei: Diagnostics, Demography and Formation, Springer, Berlin/Heidelberg, pp. 3-15, 2001.

[9] Schutz, Bernard F. (2003), Gravity from the ground up, Cambridge University Press, ISBN 0-521-45506-5

[10] Davies, P. C. W,. "Thermodynamics of Black Holes", Reports on Progress in Physics, Rep. Prog. Phys., Vol. 41, 1978. Printed in Great Britain.

[11] Heusler, M, "Stationary Black Holes: Uniqueness and Beyond",Living Reviews in Relativity Retrieved 2011.

[12] Mostafa Nemati, et al., "Black Holes Algorithm: A Swarm Algorithm inspired of Black Holes for Optimization Problems", IAES International Journal of Artificial Intelligence (IJ-AI), Vol 2, No 3, September (2013). 